\title{
Delivering and evaluating the multiple flood risk benefits in Blue-Green Cities: an interdisciplinary approach
}

\author{
E. Lawson ${ }^{1}$, C. Thorne ${ }^{1}$, S. Ahilan ${ }^{2}$, D. Allen ${ }^{3}$, S. Arthur ${ }^{3}$, \\ G. Everett ${ }^{4}$, R. Fenner ${ }^{5}$, V. Glenis ${ }^{6}$, D. Guan ${ }^{7}$, L. Hoang ${ }^{5}$, \\ C. Kilsby ${ }^{6}$, J. Lamond ${ }^{4}$, J. Mant ${ }^{8}$, S. Maskrey ${ }^{1}$, N. Mount ${ }^{1}$, \\ A. Sleigh ${ }^{2}$, L. Smith ${ }^{9}, 10$ \& N. Wright ${ }^{2}$ \\ ${ }^{1}$ School of Geography, University of Nottingham, UK \\ ${ }^{2}$ School of Civil Engineering, University of Leeds, UK \\ ${ }^{3}$ School of the Built Environment, Heriot-Watt University, UK \\ ${ }^{4}$ Construction and Property Research Centre, \\ University of the West of England, UK \\ ${ }^{5}$ Department of Engineering, Cambridge University, UK \\ ${ }^{6}$ School of Civil Engineering and Geosciences, Newcastle University, UK \\ ${ }^{7}$ School of Earth and Environment, University of Leeds, UK \\ ${ }^{8}$ The River Restoration Centre, Cranfield University, UK \\ ${ }^{9}$ Centre for the Analysis of Time Series, \\ London School of Economics \& Political Science, UK \\ ${ }^{10}$ Pembroke College, University of Oxford, UK
}

\begin{abstract}
A Blue-Green City aims to recreate a naturally-oriented water cycle while contributing to the amenity of the city by bringing water management and green infrastructure together. The Blue-Green approach is more than a stormwater management strategy aimed at improving water quality and providing flood risk benefits. It can also provide important ecosystem services and socio-cultural benefits when the urban system is in a non-flood condition. However, quantitative evaluation of benefits and the appraisal of the relative significance of each benefit in a given location are not well understood. The Blue-Green Cities Research Project aims to develop procedures for the robust evaluation of the multiple
\end{abstract}


functionalities of Blue-Green Infrastructure (BGI) components within flood risk management (FRM) strategies. The salient environmental challenge of FRM cuts across disciplinary boundaries, hence an interdisciplinary approach aims to avoid partial framing of the ongoing FRM debate. The Consortium, comprising academics from eight UK institutions and numerous disciplines, will investigate linkages between human behaviours and physical processes, and produce an urban flood model to simulate the movement of water and sediment through Blue-Green features. Individual and institutional agents will be incorporated into the model to illustrate how their behavioural changes impact on flooding and vice versa. A methodological approach for evaluating the interaction of urban FRM components within the wider urban system will be developed and highlight where, when and to whom a range of benefits may accrue from BGI and other flood management interventions under non-flood and flood conditions. Recognition of the compound uncertainties involved in achieving multiple benefits at scale will be part of the ongoing robust method of uncertainty evaluation. The deliverables will be applied to a chosen demonstration case study, Newcastle, UK, in the final year of the project (2015). This paper will introduce the Blue-Green Cities Research Project and the novel, interdisciplinary framework that is adopted to investigate multiple FRM benefits.

Keywords: Blue-Green Cities, flood risk management, multiple benefits, interdisciplinary, green infrastructure, ecosystem services, pluvial flooding, urban planning, and agent-based modelling.

\section{Introduction}

The combined impacts on social, economic and environmental systems make flooding one of the World's most serious hazards. Over 2.4 million properties in England alone are at risk of fluvial or coastal flooding, with a further 2.8 million properties susceptible to surface water flooding [1]. Increasing frequency and magnitude of intense precipitation events in future decades are predicted to increase flooding and damages incurred [2], particularly in cities where the consequences of flooding are especially severe. Increasing urbanisation, economic growth, and the concomitant increase in impermeable surfaces will further exacerbate the urban flood risk. There is thus a demand for new and innovative research that can help reduce the probability and/or consequences of urban flooding while helping cities become more resilient and able to adapt to new flood risks imposed by climate change [3] and economic development.

Non-traditional measures for flood risk management (FRM) aim to reduce the amount of water entering man-made drainage systems and offer an alternative to traditional grey infrastructure (e.g. piped drainage and waste water treatment systems for pollution control). Natural measures are gaining increasing support as efforts are made to better integrate the water cycle with urban design and development needs, particularly in light of future climate change and the limited adaptability of grey infrastructure to events that exceed the design standard. A move towards urban water management that holistically considers the environmental, social and economic consequences of different strategies is 
illustrated by efforts to adopt water-sensitive urban design (WSUD) and incorporate this in UK policy [4]. WSUD regards urban surface water runoff as a resource, rather than a nuisance, diverging from the traditional paradigm of removing surface water quickly and efficiently to advocating the protection of urban water resources and generation of multiple benefits from multifunctional landuse [5]. Such benefits may be achieved at lower costs if water services are linked with other urban infrastructure systems [6]. WSUD and investment in green infrastructure in the UK is in its infancy yet advances in Australia [7], other European countries (including Scotland) [8], and the US [9], provide illustrative examples of successful incorporation. However, the pace of transition to connected and adaptive practices in urban water management, which integrate FRM with new forms of sustainable and socially equitable urban planning and design, must increase. Research projects, such as the 'Blue Green Dream' [10], are helping advance the paradigm shift away from grey infrastructure yet widespread implementation requires negotiation of the "Blue-Green" vision by all representative stakeholders, and subsequent ownership of that vision.

The integration of urban design with various disciplines of engineering and environmental sciences defines the WSUD process [5] and illustrates the importance of utilising expertise from multiple disciplines for effective research, planning and application. Holistic, interdisciplinary approaches are increasingly endorsed as the most effective way to provide sound science and tackle the environmental and societal problem of flooding while avoiding partial framing of the FRM debate [11]. This paper introduces the Blue-Green Cities Research Project and the novel interdisciplinary framework that places people, society and their interactions with FRM policy at the heart of the research. Blue-Green Cities Research is founded on strong internal and external communication networks and will develop procedures for the robust evaluation of the multiple functionalities of Blue-Green Infrastructure (BGI) components within FRM strategies. We aim to generate novel findings on the behaviour and attitudes of individuals and institutions to changes in the management practices of the urban water system, and will subsequently apply this in a demonstration case study.

\section{The Blue-Green Cities concept}

A Blue-Green City aims to recreate a naturally oriented water cycle while contributing to the amenity of the city by bringing water management and green infrastructure together [12]. This is achieved by combining and protecting the hydrological and ecological values of the urban landscape while providing resilient and adaptive measures to deal with flood events (Fig 1). Key functions include restoring natural drainage channels, mimicking pre-development hydrology and improving water quality, reducing imperviousness, and increasing infiltration, surface storage and the use of water retentive plants [13].

Blue infrastructure includes the ponds, flowing waterways, wet detention basins and wetlands that exist within the drainage network. Green infrastructure refers to natural land and plant based ecological treatment systems and processes. This comprises open spaces, parks, recreation grounds, woodlands, gardens, green 
corridors, vegetated ephemeral waterways and planted drainage assets that undergo a wet/dry cycle due to runoff flow, e.g. green roofs and street trees. BGI provides a range of services that include; water supply, climate regulation, pollution control and hazard regulation (blue services/goods), crops, food and timber, wild species diversity, detoxification, cultural services (physical health, aesthetics, spiritual), plus abilities to adapt to and mitigate climate change [10]. Such services, and hence the benefits that are directly attributed to them, are often absent where traditional grey infrastructure is used to manage surface water and flooding. The Blue-Green concept places value on the connection and interaction of blue and green assets and proposes a network of interconnected BGI to convey, treat and manage urban runoff and flooding, while maximising the accrual of multiple benefits. However, the lack of space in highly urbanised catchments may restrict the incorporation and retrofitting of BGI, and hence, grey infrastructure also has a role in the Blue-Green concept, particularly for high magnitude events with a low probability of occurrence.

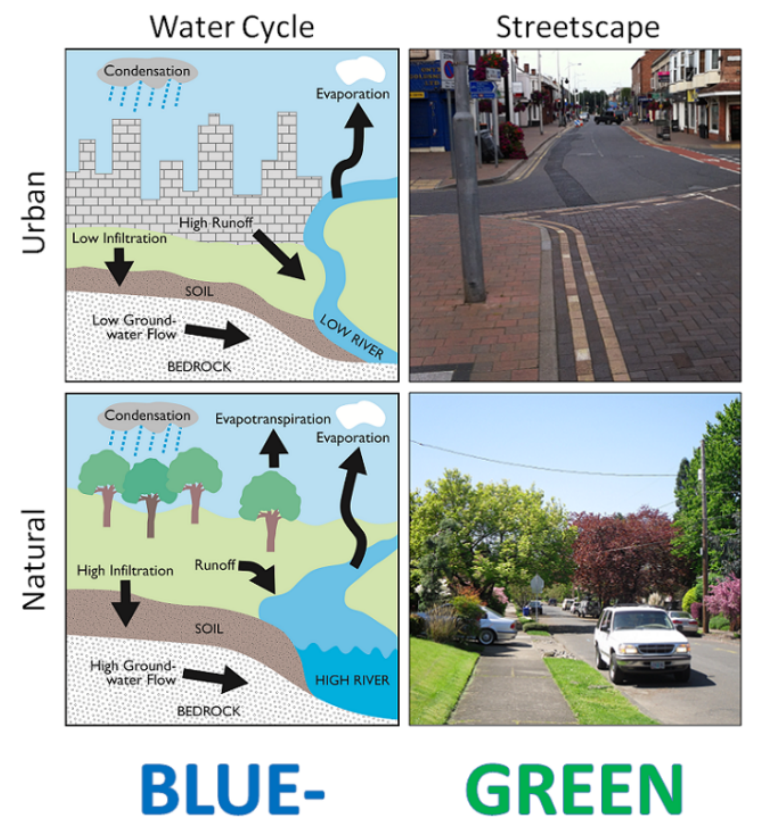

Figure 1: Comparison of the hydrologic (water cycle) and environmental (streetscape) attributes in conventional (upper) and Blue-Green Cities.

\subsection{Multiple benefits of the Blue-Green Infrastructure}

Blue-Green Cities may generate a multitude of environmental, ecological, sociocultural and economic benefits when the urban system is in both flood and non- 
flood states. BGI that perform to the design standard will fulfil the primary goal of reducing the risk of surface water inundation during a flood event. In addition, when in the flood state, BGI may reduce water pollution and improve water quality, help control the water supply and prevent the cascade of negative socioeconomic impacts that generally occur in the aftermath of a flood, e.g. high repair costs, displacement from homes, damage to health, decline in business and reduced economic prosperity. Furthermore, construction and maintenance of BGI is often cheaper than the grey alternative, as illustrated by Portland's "Green streets" project to reduce stormwater runoff and the risk of combined sewer overflow. \$250 million in hard infrastructure costs was saved through the design and landscaping of soil and plants into the urban streetscape to aid infiltration and reduce peak stormwater flow (at a cost of $\$ 8$ million) [14].

Blue-Green Cities also offer numerous benefits when the system is in a nonflood state. Environmental benefits include; reduction in the urban heat island effect, improved air quality, noise reduction, carbon sequestration and a carbon emission reduction potential through avoiding highly carbon intensive alternatives, groundwater recharge, increased biodiversity, habitat enhancement and related ecosystem services. Socio-cultural benefits include; traffic calming and road safety, reduction in water demand and water recycling, improved health and wellbeing, attractive landscape, improved quality of place, crime reduction and education potential. BGI may also augment the ability of cities to mitigate and adapt to climate change [14] and is frequently a key component of economic regeneration projects to improve the liveability of urban environments [15].

\section{Interdisciplinary research and the Blue-Green Cities Project}

The potential benefits of the Blue-Green approach span the environmental, socioeconomic and cultural spheres of the urban environment, and hence, require an interdisciplinary team to fully evaluate. Similarly, issues of FRM do not fit neatly into a disciplinary boundary and an interdisciplinary approach is particularly suitable. Interdisciplinary research may also be more responsive to public needs and concerns and a valid means of generating science policy [11]. 'Interdisciplinarity' is a highly debated term yet most definitions refer to the integration of disciplines within a research environment driven by interactions and joint-working amongst academics motivated by a common problem-solving purpose $[11,16]$. The field of a single discipline is therefore transgressed by collaboratory working [17]. Similarly, an interdisciplinary approach can help develop FRM policies that address the issue of future climate change and resiliency; changes cannot solely be made through technological capabilities but must also address variability in social expectations and lifestyles [18].

'Blue-Green Cities' is a highly interdisciplinary project funded by the Engineering and Physical Sciences Research Council (EPSRC, February 2013January 2016). The Research Consortium comprises academics from eight UK institutions and numerous disciplines; hydrodynamics, geomorphology, ecology, physics, social sciences, engineering, and environmental economics. The main 
research components (Fig 2) are denoted by Work Packages (WP), held together by a strong communications package to promote interdisciplinarity and coherent, integrated results, based on shared conceptual, methodological and theoretical ideas [19]. A strong communications network, both internally and with external stakeholders, is central to our goal to investigate the linkages between human behaviours, physical processes and policy constraints regarding FRM. We aim to progress from the multi-disciplinary approach where discrete disciplinary work packages are completed and subsequently combined at the end of the project, with little cross-discipline engagement during the research process. Rather, we aim for data exchanges and common epistemological approaches to marry the interdisciplinary appeal with the disciplinary mastery [20]. This will create knowledge that is solution oriented and socially robust [21], and transferable to both scientific and societal practice. Co-evolution of understanding and knowledge, aided by tight integration within the team, will ensure that the sum of the whole (in terms of deliverables) exceeds the sum of the parts.

The aim of the Consortium is to develop new urban FRM strategies as part of wider, integrated planning intended to achieve urban renewal and environmental enhancement in which multiple benefits of BGI are rigorously evaluated and understood. Focussing on a common case study (Newcastle) in the third year of the project (2015) is key to visualising the Consortium aim and converging on common deliverables, with success relying on the co-production of knowledge and multi-way exchange within the Research Consortium and wider stakeholders. Communication is often ineffective and one-way between academia and endusers, e.g. key stakeholders (including decision makers) and local communities (those at risk of flooding and directly affected by decisions and hence should take an active role in decision making regarding FRM $[18,22])$. We aim to facilitate discussion and include these groups from the outset.

\subsection{Key deliverables}

Research will focus primarily on fluvial and pluvial flooding; the latter typically caused by extreme local storms and insufficient capacity of subsurface drainage networks. The Consortium is developing urban flood models that realistically represent the urban environment (land use and terrain) in its complexity. Coupled surface/sub-surface hydrodynamic models will produce inundation predictions across a range of events of different frequencies and lengths, visualised in probability maps for inundation across an urban area. Flood inundation modelling is being developed to include the movement of water through Blue-Green features such as blue and green roofs, retention ponds, permeable paving, green space and bioswales, to enable a comparison of flow velocity, depth and inundation extent before and after the adoption of BGI. BGI as a FRM strategy will be assessed by a set of scenarios including 'business and usual' (no additional BGI) and a BlueGreen future (BGI as preferred assets). 


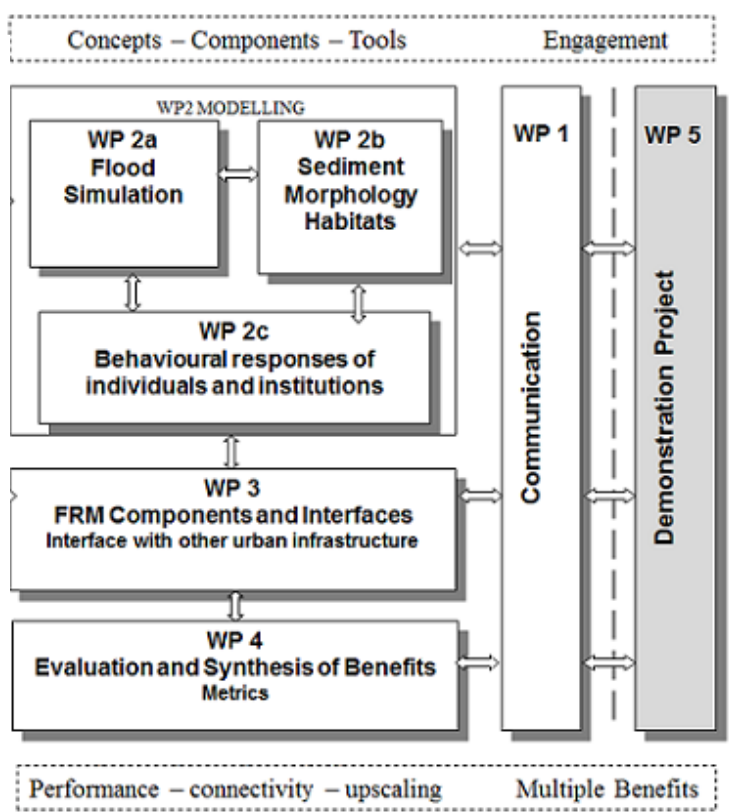

Figure 2: $\quad$ Structure of the Blue-Green Cities Research Project.

Modelling existing flood risks is being linked to semi-quantitative assessments of sediment and debris dynamics in emerging vegetated and naturalized urban drainage systems. Fieldwork will fill knowledge gaps in network forms and functions as part of a source-pathway-receptor analysis. Research is addressing the movement of sediment and debris from catchment surfaces into and through BGI, and assessing the potential for debris to block culvert trash screens. This will develop the understanding of how sediment and debris sources and transportation dynamics may impact on urban flooding. Sediment mass and volume, total suspended solids, particle density, organic matter content and tracer techniques, e.g. rare earth oxides and passive integrated transponder technology, are used to analyse the performance of drainage networks. Sediment and debris dynamics, such as entrainment, deposition, re-suspension and blockage potential at choke and pinch points, are being identified to illustrate the efficiency of the multielement urban drainage network to detain or convey sediment and pollutants from the source (urban surfaces) to receptor (receiving water body). The project will also complete an impact assessment of Blue-Green vs. grey design on habitats and biodiversity in open watercourses to advance the understanding of how morphological and ecological diversity in urban streams may be increased and ecosystem services accrued. 


\subsection{Determining agent responses to FRM and BGI}

Successful simulation of the movement of water and sediment through the urban environment will indicate design benefits of select infrastructure components and generate recommendations to achieve multiple benefits. However, the physical system cannot be assessed in isolation. Societal perceptions of the costs and benefits of different FRM approaches play an important role in progressing research into policy [22]. Interaction and involvement in the evolution of BlueGreen design by the stakeholder community is essential to the concept of BlueGreen Cities. Individual and institutional agents will be incorporated into the flood inundation model to illustrate how behavioural changes impact on flooding and vice versa. Such knowledge is crucial when making the case that agents need to be part of the decision-making process for FRM. Fieldwork will be used to identify and understand the behavioural responses of individuals and institutions to a range of FRM strategies including Blue-Green. Evidence-based rules are being developed using stated preference models to represent those behaviours and will provide the data input to an agent-based model to investigate alternative scenarios of future Blue-Green FRM strategies under different socio-economic conditions. We are developing an understanding of how agents respond to stimulus and change in the physical landscape, and how this may alter the probability of flooding. We are also interested in how agents behave in a way to reduce the consequences of flooding. Potential barriers to the implementation of FRM strategies arise depending on where and to whom the benefits of BGI accrue during times of no flood. This, and the potential for positive and negative interactions with wider urban infrastructure, may act as an incentive/disincentive for the adoption of innovative, non-traditional solutions.

\subsection{FRM components, interfaces and uncertainties}

Tools and methodologies are being developed to represent FRM and Blue-Green networks in a single urban environment, as part of a wider complex 'system of systems' that services urban communities. Series of interrelationships link energy, transportation, water (supply and wastewater), emergency services, and information and telecommunication sectors. Disrupting these dependencies can have significant socio-cultural and economic consequences that may extend to regional and national level, particularly during times of extreme flood. Research will illustrate how changes in both the physical interfaces (flood pathways and BGI) and institutional responsibilities (policy, planning and governance structures) cascade across the wider urban system, and identify intervention points to ensure rapid adoption, optimum functionality and reduced risk in other infrastructure areas. The Three Points Approach (3PA) of Fratini et al. [23] will be adopted and illustrates a more holistic process towards urban FRM that simultaneously considers technical optimisation of urban drainage systems, spatial planning to increase resiliency, and everyday performance under the green, nonflood, condition as a foundation for social preparedness. Three system states have been developed from the 3PA; non-flood (green condition), design standard, and 
extreme event (blue condition). By understanding the interactions between different urban infrastructure components under each of the three system states can we hope to highlight where, when and to whom the costs and benefits of different FRM strategies accrue.

Acceptable functioning of the flooding system is determined by meeting the standard for flood defence despite the occurrence of possible climate changes. Hence, we are also investigating how to optimise the functioning of the urban water system to cope with an uncertain future, addressing recent theory that nontraditional, Blue-Green measures may create a more resilient flooding system with respect to long-term future change $[14,15]$. Due to the non-stationarity of physical processes, a range of scenarios will be employed to investigate the success of BGI under different possible futures, acknowledging the full range of uncertainty that is inherent to the outcome. This links to an ongoing uncertainty analysis which aims to identify, and where possible, quantify uncertainty as it propagates through the model cascade. Uncertainty is inherent in all models (empirical, conceptual, and numerical) and effective buy-in from stakeholders regarding recommendations for urban FRM is dependent on transparency in the research process and acknowledgement of assumptions made. We are addressing uncertainties that we are able to reduce, uncertainties that we can track and propagate, and those we can only talk about. The evolving character of built environments combined with large uncertainty in future flood inundation, for instance, increases the complexity of modelling urban FRM strategies. Despite such limitations, we hope to identify strategies that are robust to some of the future uncertainties, help increase resilience, and generate a range of benefits.

\subsection{Evaluation and synthesis of multiple benefits}

Methodologies are being developed to assess, quantify and value the multiple benefits of adopting BGI in urban FRM strategies at both the local/regional and global/international scales. Such methodologies will also robustly evaluate the multiple functionalities of BGI components and address the inherent uncertainties of cost/benefit analysis. By evaluating the relative significance of benefits in context specific locations we aim to establish preference ratings linked to a multi criteria analysis for component selection. This will provide sound science and recommendations for design guidance to assist policy makers in the choice of FRM strategy. Despite the 2007 SuDS (Sustainable urban Drainage Systems) Manual (C697) [24] providing extensive guidance, the lack of recent UK legislation is a key barrier to the limited uptake of BGI and SuDS.

We adopt a novel method of performance appraisal against a set of diverse criteria that addresses environmental, socio-cultural and economic costs and benefits that accrue beyond the realm of effective FRM. Surface water management objectives, such as the minimization of runoff quantity, reduction of peak stormwater flows, and improvement to runoff quality may be achieved by grey or Blue-Green infrastructure. Both incur costs; capital materials, energy inputs and maintenance, yet those for BGI are typically much lower [14]. Life cycle assessment (LCA) and similar methods of economic costing are often used 
for comparison and selection of asset design [25]. Whatmore et al. [22] contend that choice of FRM solution based solely on economic viability (benefits $>$ costs) restricts the range of FRM solutions to be explored. The full net-benefit of BGI development can only be realized by a comprehensive accounting of their multiple benefits [14]. Quantitative evaluation of benefits and the appraisal of the relative significance of each benefit in a given location are not well understood. BGI is acknowledged as providing additional benefits that grey infrastructure cannot, such as counteracting urban heat island effects, reducing energy costs, creating community amenities and improving habitats [14], and multi-functional landuse is paramount to optimise BGI benefit accrual.

\subsection{Application in the demonstration case study (Newcastle, UK)}

The deliverables from Blue-Green Cities research will be exhibited in the demonstration case study, Newcastle, UK, in the final year of the project (2015) to demonstrate the applicability of the methods, measures and evaluations developed by the Consortium. Newcastle encompasses hydrological, topographic, urban density and socio-economic conditions that are representative of those found more widely in UK cities and has experienced recent major flooding events. Much of the city centre is impermeable and vulnerable to pluvial flooding, piped drainage systems are often unable to cope with intense rainfall and the risk of sewer incapacity and surcharge is relatively high. The need for increased housing provision may also reduce available greenspace in the future. Interest in BGI for FRM from key stakeholder groups plus active research into climate change adaptation and mitigation and urban greenspace [15] suggests Newcastle may be highly receptive to the Blue-Green concept.

\section{Summary}

The Blue-Green Cities Research Project adopts an interdisciplinary approach to identify and rigorously evaluate the multiple benefits of natural flood risk management strategies using Blue-Green infrastructure. This paradigm shift from traditional grey infrastructure designed to remove water as quickly as possible from the urban surface is in line with WSUD and urban water management that holistically considers the environmental, social and economic consequences FRM strategies. A Blue-Green City offers effective performance of the drainage network to achieve high levels of flood protection and resilience to some future climate change, while supporting multiple non-flood benefits, often maximised by the integration of blue and green assays and creation of networks. Throughout 2014-15 the Blue-Green Cities Research Consortium will model how changes in policy and associated agent behaviour/attitudes can impact on flooding and vice versa. This linking of physical processes to human behavioural patterns for different scenarios is highly innovative and will provide for an analysis of the urban 'system of systems' and highlight where, when and to whom the multiple benefits will accrue under different future scenarios. This will allow us to rigorously, and where possible, quantitatively, evaluate the costs and benefits of 
different strategies and appraise the relative significance of each benefit in a given location. The attitudes and perceptions of people and society towards Blue-Green and grey infrastructure is critical in demonstrating to policy makers how nontraditional infrastructure may be utilised to achieve maximum benefit while ensuing 'agents' become part of the decision-making process. The applicability of the research methods will be tested in the demonstration case study (Newcastle, UK) and will endeavour to incorporate the understanding and interest of key stakeholders in urban FRM and connect this with the potential impact of adopting the Blue-Green vision in a practical, real-life setting.

\section{References}

[1] Bennett, O., Flood defence spending in England, Standard Note: 14th March 2013, House of Commons Library, London, 2013.

[2] Bates, B., Kundzewicz, Z.W., Wu, S., \& Palutihof, J., (eds). Climate Change and Water, Technical Paper, Intergovernmental Panel on Climate Change (IPCC), 2008.

[3] Wilby, R.L. \& Keenan, R., Adapting to flood risk under climate change. Progress in Physical Geography, 36(3), pp. 348-378, 2012.

[4] Ashley, R., Lain, L., Ward, S., Shaffer, P., Walker, L., Morgan, C., Saul, A., Wong, T., Moore, S., Water-sensitive urban design: opportunities for the UK. Proceedings of the ICE-Municipal Engineer, 166(2), pp. 65-76, 2013.

[5] Wong, T., \& Brown, R., The water sensitive city: principles for practice. Water Science \& Technology, 60(3), pp. 673-682, 2009.

[6] Potter, K., Ward, S., Shaw, D., Macdonald, N., White, I., Fisher, T., Butler, D., \& Kellagher, R., Engineers and planners: sustainable water management alliances. Proceedings of the ICE-Engineering Sustainability, 164(4), pp. 239-247, 2011.

[7] Brown, R.R., \& Clarke, J. M., Transition to water sensitive urban design: The story of Melbourne, Australia. Facility for Advancing Water Biofiltration, Monash University Melbourne, Australia, 2007.

[8] Stahre, P., Blue-green fingerprints in the city of Malmö, Sweden: Malmö's way towards a sustainable urban drainage. VASYD, Malmö, Sweden, 2008.

[9] Portland "Grey to Green" initiative; The City of Portland Environmental Services website, http://www.portlandoregon.gov/bes/47203

[10] Maksimović, S., Xi Liu, S., \& M. Lalić, M., Blue Green Dream Project's Solutions for Urban Areas in the Future. Reporting for Sustainability, pp. 49-54, 2013, available online at http://www.sciconfemc.rs /PAPERS/BLUE\%20GREEN\%20.pdf

[11] Lowe, P. \& Phillipson, J., Reflexive interdisciplinary research: the making of a research programme on the rural economy and land use. Journal of Agricultural Economics, 57(2), pp. 165-184, 2006.

[12] Hoyer, J., Dickhaut, W., Kronawitter, L., \& Weber, B., Water sensitive urban design: principles and inspiration for sustainable stormwater 
management in the city of the future. Jovis Publications: Berlin, Germany, 2011.

[13] Novotny, V., Ahern, J., \& Brown, P., Water centric sustainable communities: planning, retrofitting and building the next urban environment. Wiley Publishing.com, 2010.

[14] Foster, J., Lowe, A., \& Winkelman, S., The value of green infrastructure for urban climate adaptation. Center for Clean Air Policy, February, 2011, Available online at http://dev.cakex.org/sites/default/files/Green Infrastructure_FINAL.pdf

[15] Planning for the Future, Core Strategy and Urban Core Plan for Gateshead and Newcastle upon Tyne, NewcastleGateshead City Council, 2013. Available online at https://www.newcastle.gov.uk/planning-andbuildings/planning-policy/core-strategy-and-urban-core-plan

[16] Klein, J.T., A taxonomy of interdisciplinarity. The Oxford handbook of interdisciplinarity, 15, 2010.

[17] Balsiger, P.W., Supradisciplinary research practices: history, objectives and rationale. Futures, 36(4), pp. 407-421, 2004.

[18] Ashley, R., Blanksby, J., Chapman, J., \& Zhou, J., Towards integrated approaches to reduce flood risk in urban areas. Advances in Urban Flood Management, pp. 415-432, 2007.

[19] OECD (Organisation for Economic Cooperation and Development), Interdisciplinarity in Science and Technology, In: Directorate for Science, Technology and Industry. OECD: Paris, 1998.

[20] Klein, J.T., Evaluation of interdisciplinary and transdisciplinary research: a literature review. American journal of preventive medicine, 35(2), pp. 116$123,2008$.

[21] Gibbons, M., Science's new social contract with society. Nature, 402, pp. 81-84, 1999.

[22] Whatmore, S.J., Odoni, N., Ward, N., \& Bradley, S., Coproducing flood risk knowledge: redistributing expertise in critical participatory modelling. Environment and Planning A, 43, pp. 1617-1633, 2011.

[23] Fratini, C., Geldof, G. D., Kulck, J., \& Mikkelsen, P. S., Three Points Approach (3PA) for urban flood risk management: A tool to support climate change adaptation through transdisciplinarity and multifunctionality. Urban Water Journal, 9(5), pp. 317-331, 2012.

[24] Woods-Ballard, B., Kellagher, R., Martin, P., Jeffries, C., Bray, R., \& Shaffer, P., The SUDS manual. CIRIA, London, 2007.

[25] Wang, R., Eckelman, M. J., \& Zimmerman, J. B., Consequential Environmental and Economic Life Cycle Assessment of Green and Gray Stormwater Infrastructures for Combined Sewer Systems. Environmental Science \& Technology, 47(19), pp. 11189-11198, 2013. 